\title{
THE EFFECTS OF FORM AND ORIENTATION ON ENERGY PERFORMANCE OF RESIDENTIAL BUILDINGS IN GHANA
}

\author{
C. Koranteng and E.G. Abaitey \\ Department of Architecture, \\ Kwame Nkrumah University of Science and Technology, Kumasi, Ghana
}

\begin{abstract}
The form and orientation of a building can have an effect on energy performance. The difficulty has been to find the most energy efficient form-aspect ratio. In this paper, a volume with different aspect ratios has been used to investigate the effect on energy performance (cooling load). The volume used is of the same construction and an hourly dynamic simulation programme was used for the analysis. It was evident that the square form was the most energy efficient whiles elongated forms used much energy. However, since spaces could warm up when oriented towards the east and west, the authors further recommend a detailed look into the function of spaces in design schemes and the use of simulation for design alternatives.
\end{abstract}

Keywords: Form, Orientation, Energy Performance, Cooling Load

\section{INTRODUCTION}

Energy supply has not been able to meet the demand in Ghana and a load shedding exercise was implemented in the year 2006 which ran through part of 2007 . With the growth in demand for housing with a resulting growth in energy use, the building sector could contribute immensely to sustainable use of energy by adopting sustainable design strategies.

The form and orientation of a building has effects on energy performance. It is the concern of the authors to use simulation as an investigative tool in shedding more light on how far form and orientation relate to energy performance. They also intend to recommend the most effective form and orientation in terms of reducing energy consumption (cooling load) in buildings.
The world's energy crisis in 1973 and the inability of developing countries to guarantee the supply of energy due to its scarcity have triggered studies into the sustainable use of energy. The world's reserves of crude oil are getting depleted at a rapid rate and this has brought about the increase in oil prices. Light sweet crude oil hit a record of 100 dollar per barrel on the second day of the year 2008 (WNN 2008) and by the third week of March 2008, the price of a barrel rose to 104 dollars. The high oil price has a negative effect on the economies of developing countries.

The way forward is to look at sustainable and efficient means in the design and use of our built environment. The results in this paper should help promote the use of passive means 
and strategies in the reduction of energy use and cooling loads in buildings.

The question of orientation and form has received different answers and opinions by researchers. Whereas some recommend an orientation to the prevailing wind direction (Lauber 2005, Koenigsberger et al., 1974), others are of the view that the exact orientation is not a critical principle to adhere to when it comes to design (Salmon 1999). Rather, the function, configuration of spaces and the properties of the building envelope have to be given more attention. Different forms and aspect ratios (the width to length ratio, especially for elongated buildings) have also been recommended.

Buildings, through their envelope, should be able to maintain indoor comfort and provide protection. In this regard, the exact solar orientation is not critical, even though elongated buildings should be oriented towards the south. This is plausible, since solar radiation from the eastern and western sides is more intense and should be avoided. A proposal of elongated buildings to be oriented towards a $+/-30^{\circ}$ angle from the prevailing wind direction has been suggested for warm and humid countries and a recommendation for air-conditioned buildings to have their shells insulated, windproof and to be airtight. This recommendation would mean an orientation of elongated, air-conditioned buildings towards the southeast/northwest since the prevailing wind direction in Ghana is from the southwest and northeast.

Szokolay (2004) recommends an aspect ratio of 1: 1.3 to 2.0 for elongated buildings depending on the climate and walls with major openings (on the elongated side) to face within $45^{\circ}$ of the prevailing wind direction. This is $15^{\circ}$ more than what Lauber (2005), suggested on the above issue. On the other hand, this implies an optimum orientation of the elongated sides facing north or south, and a thermally inappropriate direction of openings facing the western sun.

For a shape that is spread out, the use of ambient energy and orientation is an important is- sue; whiles compact forms tend to minimise the influence of the external environment, thereby ignoring orientation. The more a form is spread out, the larger the surface area and area that could be exposed to solar radiation. Therefore, for such forms, orientation has to be away from the east and west.

A ratio of 1: 1.64 is also recommended by Watson (1983), but orientation ceases to be an issue when thermal resistance of the building envelope increases.

Generally, with elongated buildings, an orientation to south/north and to the prevailing wind direction with some degree of freedom has been suggested. Most researchers have not been clear in their recommendations of orientation for square and air-conditioned buildings. The perception with square buildings is that there is the need for functional analysis of the spaces for justification of the orientation of the space.

The authors would like to use simulation as a tool (EDSL, 2008) to find out the relationships between form, orientation and energy performance.

\section{MATERIALS AND METHODS}

A closed prototype volume of $4 \times 4 \times 4$ metres with an area of $16 \mathrm{~m}^{2}$ was used as a baseline model for the simulation (Fig. 1).

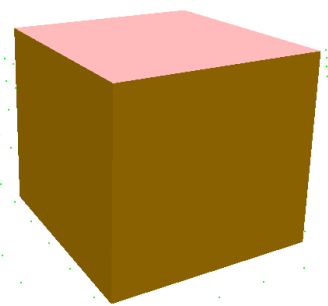

\section{Fig. 1: Tas model of prototype volume with aspect ratio 1:1}

The volume with different aspect ratios was altered at alternate angles of $45^{\circ}$ to find the effects of orientation on energy performance, precisely, cooling load (Table 1.). 
Table 1: Options on Form Ratios

\begin{tabular}{cc}
\hline Aspect Ratios & width x length $(\mathbf{m})$ \\
\hline $1: 1.0$ & $4.0000 \times 4.0000$ \\
$1: 1.5$ & $3.2660 \times 4.8990$ \\
$1: 2.0$ & $2.8284 \times 5.6568$ \\
$1: 2.5$ & $2.5298 \times 6.3245$ \\
$1: 3.0$ & $2.3094 \times 6.9282$ \\
\hline
\end{tabular}

The effect of windows, doors, roofing, etc on cooling load was avoided through the use of solid walls with the same conductance for all building elements. The construction for the building elements is a $20 \mathrm{~cm}$ monolithic wall with plaster-block-plaster composition having a solar absorptance value of 0.80 and conductance of $10.933 \mathrm{w} / \mathrm{m}^{2 \circ} \mathrm{C}$ (watt per square metre degree Celsius).

The terrain type was assumed rural and a standard calendar from Monday through Sunday was used.

The internal condition parameters were: infiltration $0.4 \mathrm{ac} / \mathrm{h}$ (air change per hour), lighting gain $5 \mathrm{w} / \mathrm{m}^{2}$ (watt per square meter), occupancy sensible heat gain $4 \mathrm{w} / \mathrm{m}^{2}$ and an equipment sensible heat gain value of $3 \mathrm{w} / \mathrm{m}^{2}$.

The thermostat was set to start cooling when indoor temperature exceeded $27^{\circ} \mathrm{C}$ and to start heating when room temperatures got below $20^{\circ}$ C.

A weather file for Kumasi (latitude $6.75^{\circ} \mathrm{N}$ and longitude $-1.58^{\circ} \mathrm{N}$ ), Ghana was used as a basis to run the simulation (Meteotest, 2008).

\section{RESULTS AND DISCUSSION \\ Aspect Ratio 1:1 (square) \\ North Angle at $0^{\circ}$ and $180^{\circ}$}

On the above north angle degrees, the maximum cooling load per month of $15 \mathrm{kWh} . \mathrm{m}^{-}$ ${ }^{2}$ month $^{-1}$ (kilo watt hour per square metre per month) was recorded in the month of March and the minimum of $2 \mathrm{kWh} \cdot \mathrm{m}^{-2} \mathrm{month}^{-1}$ in the months of July, August and September. From the month of May, cooling loads fell drastically from $14 \mathrm{kWh} . \mathrm{m}^{-2} \mathrm{month}^{-1}$ to $6 \mathrm{kWh} \cdot \mathrm{m}^{-2} \mathrm{month}^{-1}$ (Fig. 2). The fall was because of the onset of

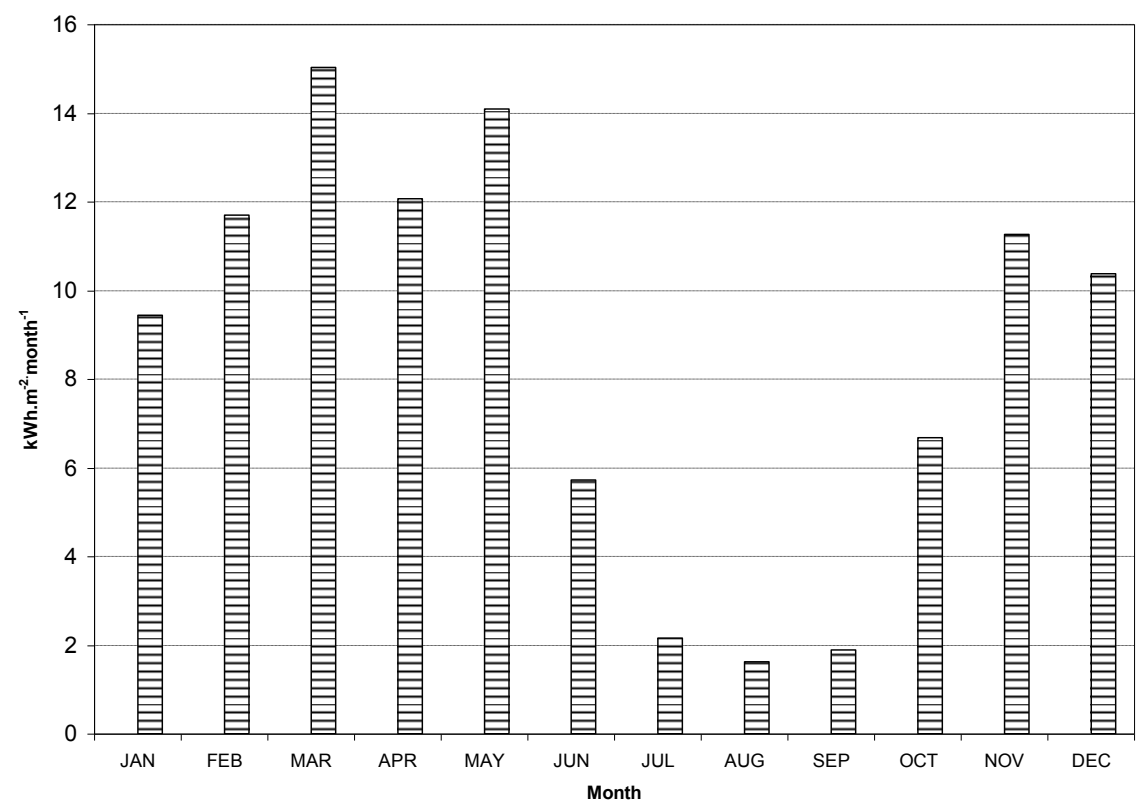

Fig. 2: Monthly cooling loads per area at north angle of $0^{\circ} / 180^{\circ}$ (aspect ratio $1: 1$ ) 
rains causing temperatures to fall. The total cooling load was 102.07 kWh.m ${ }^{-2} \mathrm{a}^{-1}$ (kilowatthours per square metre per annum) with the north angle at $0^{\circ}$ and $180^{\circ}$.

\section{North Angle at $45^{\circ}$ and $225^{\circ}$}

The maximum cooling loads per month of 16 $\mathrm{kWh} . \mathrm{m}^{-2}$ month $^{-1}$ was recorded in March at the above north angles. This was an increment of 1 $\mathrm{kWh} . \mathrm{m}^{-2}$ as compared to the $0^{\circ}$ north angle (Fig. 3). The rapid change from the values in May through June, July, August to September shows a similar pattern to the north angles of $0^{\circ} / 180^{\circ}$.

The total cooling load was 103.17 kWh.m $\mathrm{m}^{-2} \mathrm{a}^{-1}$ The increment of $1.10 \mathrm{kWh} . \mathrm{m}^{-2} \mathrm{a}^{-1}$ could be due to the fact that a larger façade area was exposed to solar radiation, as compared to the case in the previous north angles (Watson, 1983).

North Angle at $90^{\circ}$ and $270^{\circ}$

With the north angles above, a similar pattern was again observed. Annual cooling loads reduced by $0.99 \mathrm{kWh} \cdot \mathrm{m}^{-2} \mathrm{a}^{-1}$ to a value of 102.18 $\mathrm{kWh} \cdot \mathrm{m}^{-2} \mathrm{a}^{-1}$. The cooling load value at $90^{\circ} / 270^{\circ}$ is similar to the load at the $0^{\circ} / 180^{\circ}$. The difference in loads is so small that one cannot confidently recommend an orientation of north/south over east/west (Salmon, 1999).

\section{North Angle at $135^{\circ}$ and $315^{\circ}$}

The above north angles registered 103.17 $\mathrm{kWh} . \mathrm{m}^{-2} \mathrm{a}^{-1}$. This value was not different from that recorded for the $45 / 225^{\circ}$ angles. Therefore, none of the orientations could be preferred over the other. Even though the loads are a bit higher, they cannot be called significant.

Summary of results on the Aspect Ratio (1:1)

The summary (Fig 4.), shows the minimum cooling loads at north angles $0,90,180$ and 270 degrees. The maximum load was 103.17 $\mathrm{kWh} . \mathrm{m}^{-2} \mathrm{a}^{-1}$ and a minimum of $102.07 \mathrm{kWh} . \mathrm{m}^{-}$ ${ }^{2} \mathrm{a}^{-1}$ was recorded. Averagely, a load of 102.65 $\mathrm{kWh} . \mathrm{m}^{-2} \mathrm{a}^{-1}$ and a standard deviation of 0.56

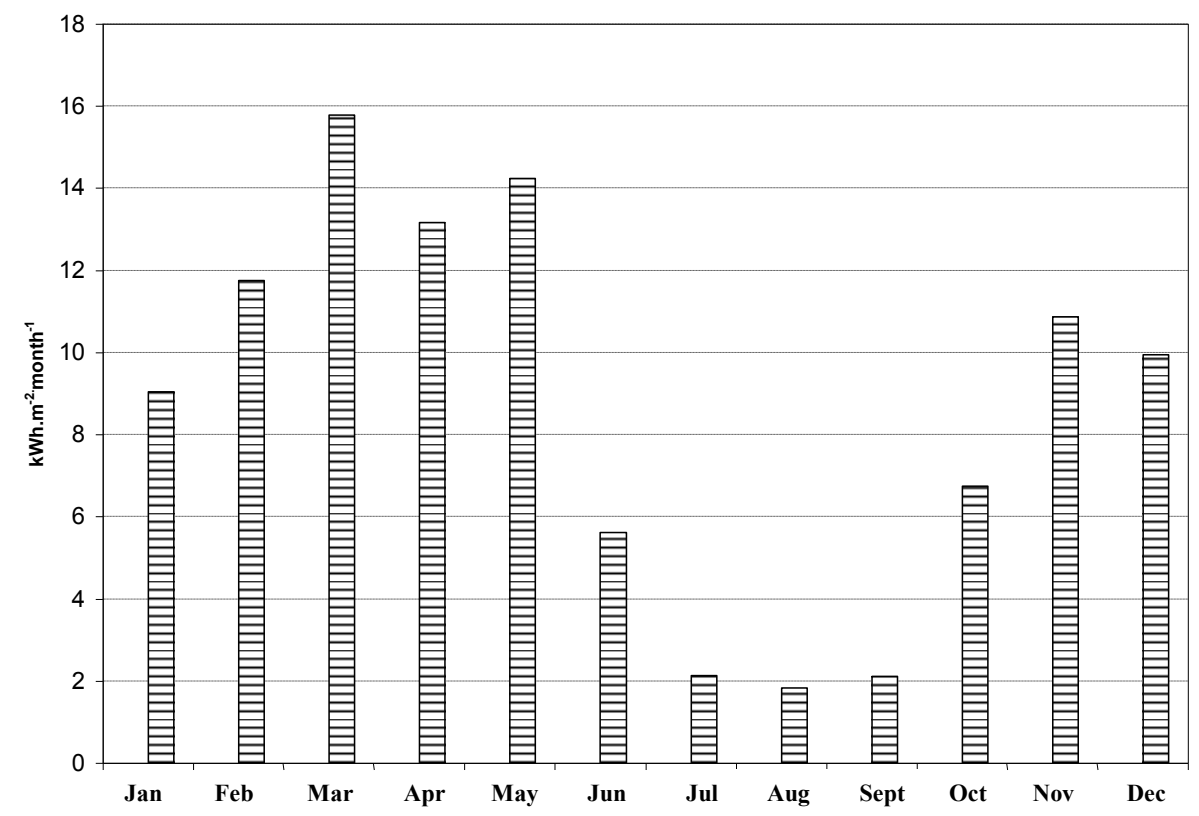

Fig. 3: Monthly cooling loads per area at north angle of $45^{\circ} / 225^{\circ}$ (aspect ratio $1: 1$ ) 


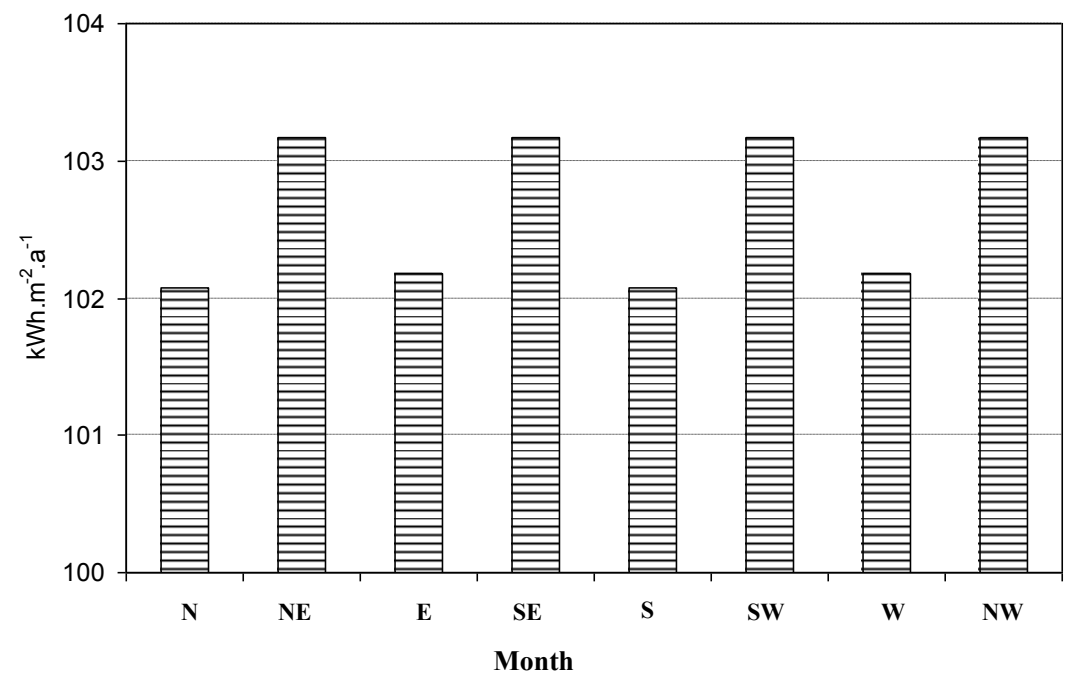

Fig. 4: Annual cooling loads per area at different north orientation angles (aspect ratio 1:1)

shows the closeness of the values of the cooling loads for all the north angles (Table 2.).

The rank of preferred north angle orientations in Table 2, suggest an orientation towards the north/south and east/west as most preferred, followed by any of the following; northeast, southeast, northwest and southwest which recorded similar values. This order shows an increase in cooling loads of $0.11 \%$ and $1.08 \%$ relative to the lowest cooling load (north angle of $0^{\circ} / 180^{\circ}$ ) of $102.07 \mathrm{kWh} \cdot \mathrm{m}^{-2} \mathrm{a}^{-1}$.

Since the differences are not significant, all orientations can be confidently recommended, preferably a north, south, east and west for airconditioned buildings on a square plan (Hawkes, 1996). However, the spatial disposition and functions of the spaces must be consid- ered for indoor comfort purposes (Givoni, 1981). Generally, with square buildings, the term orientation is applicable in effect not to the building as a whole but to its different rooms.

\section{Aspect Ratio 1:1.5 \\ North Angle at $0^{\circ}$ and $180^{\circ}$}

At the above north angles, the peak in March of $15 \mathrm{kWh} . \mathrm{m}^{-2}$ month $^{-1}$ was the same as when the aspect ratio was $1: 1$. The cooling loads in July through to September remained around the 2 kWh.m ${ }^{-2}$ month $^{-1}$ (Fig. 5).

The annual cooling loads reached 101.62 $\mathrm{kWh} \cdot \mathrm{m}^{-2} \mathrm{a}^{-1}$ on both north angles. This also represents a slight decrease of $0.45 \mathrm{kWh} . \mathrm{m}^{-2} \mathrm{a}^{-1}$ to the aspect ratio $1: 1$ on the $0^{\circ} / 180^{\circ}$ north an-

Table 2: Rank of Preferred North Angle Orientation (with 1 being the most and 3 the least preferred orientation) on the Aspect Ratio (1:1)

\begin{tabular}{cccc}
\hline Rank & North angles $\left(^{\circ}\right)$ & $\begin{array}{c}\text { Cooling loads } \\
\left(\mathbf{k W h . m}^{-\mathbf{2}} \mathbf{a}^{-\mathbf{1}}\right)\end{array}$ & $\begin{array}{c}\text { Percentage change relative to } \\
\text { lowest cooling loads (\%) }\end{array}$ \\
\hline 1 & $0 / 180$ & 102.07 & - \\
2 & $90 / 270$ & 102.18 & 0.11 \\
3 & $45 / 225,135 / 315$ & 103.17 & 1.08 \\
\hline
\end{tabular}




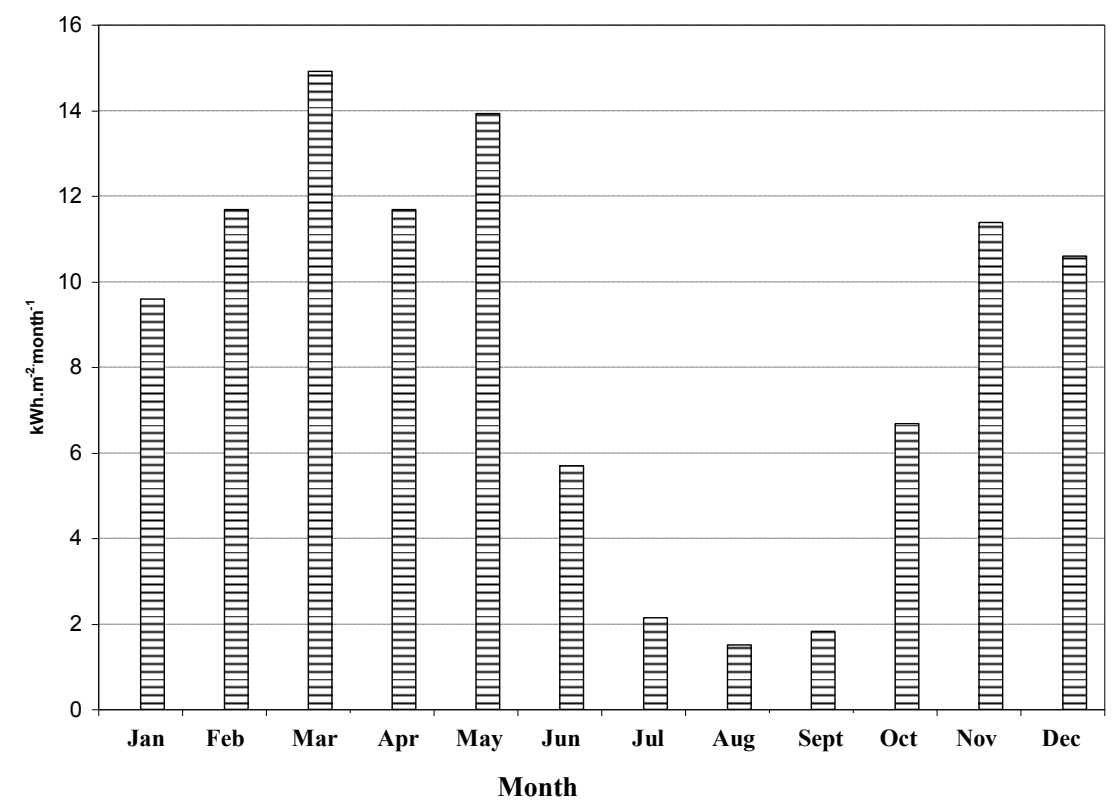

Fig.5: Monthly cooling loads per area at $0^{\circ} / 180^{\circ}$ north orientation (aspect ratio $1: 1.5$ )

gles. This implies that a decrease in the lengths of the east/west walls compared to the north/ south walls will tend to slightly reduce the cooling load at this orientation.

North Angle at $45^{\circ}$ and $225^{\circ}$

Comparatively, the pattern in monthly loads remained unchanged. The maximum monthly load was $16 \mathrm{kWh} \cdot \mathrm{m}^{-2} \mathrm{month}^{-1}$ and the minimum $2 \mathrm{kWh} \cdot \mathrm{m}^{-2} \mathrm{month}^{-1}$ (Fig. 6). The annual cooling load increased from $101.62 \mathrm{kWh} \cdot \mathrm{m}^{-2} \mathrm{a}^{-1}$ for the north/south orientation to $105.55 \mathrm{kWh} \cdot \mathrm{m}^{-2} \mathrm{a}^{-1}$. This represented an increase of $3.93 \mathrm{kWhm}^{-2} \mathrm{a}^{-1}$. Even though this increase is not so high, it could still be significant in large-scale buildings and therefore cannot be recommended as the best option of orientation

\section{North angle at $90^{\circ}$ and $270^{\circ}$}

The monthly and annual cooling loads recorded for the above angles further increased compared to those recorded for the north angles at $0^{\circ} / 180^{\circ}$ to the above angles. The annual cooling load increased to $107.41 \mathrm{kWh} \cdot \mathrm{m}^{-2} \mathrm{a}^{-1}$ representing a difference of $1.86 \mathrm{kWh} \cdot \mathrm{m}^{-2} \mathrm{a}^{-1}$ from the $45^{\circ} / 225^{\circ}$ north angle orientations. The difference increased to $5.79 \mathrm{kWh} \cdot \mathrm{m}^{-2} \mathrm{a}^{-1}$ when compared with the north angle orientation of $0^{\circ} / 180^{\circ}$. This makes this orientation undesirable and therefore should be avoided in design schemes.

\section{North angle at $135^{\circ}$ and $315^{\circ}$}

The cooling load decreased to an annual value of $105.62 \mathrm{kWh} \cdot \mathrm{m}^{-2} \mathrm{a}^{-1}$ at the above north angle orientations. The decrease was $1.79 \mathrm{kWh} \cdot \mathrm{m}^{-2} \mathrm{a}^{-1}$ from the previous north angle orientations. However, a difference of $0.07 \mathrm{kWh} \cdot \mathrm{m}^{-2} \mathrm{a}^{-1}$ was registered when compared with the north angle orientations at $45^{\circ} / 225^{\circ}$. This was not significant and cannot be recommended as a preferred orientation over the $45^{\circ} / 225^{\circ}$ north angle orientations. .

\section{Summary of results on the Aspect Ratio (1:1.5)}

From the summary (Fig. 7), the minimum cooling load was at an orientation towards the north and south. The maximum loads were from orientations towards the east and west. The diago- 
nal angles show similar values and therefore a preference in orientation cannot be recommended of one over the other. The maximum cooling load was $107.41 \mathrm{kWh} \cdot \mathrm{m}^{-2} \mathrm{a}^{-1}$ and the minimum was $101.62 \mathrm{kWh} \cdot \mathrm{m}^{-2} \mathrm{a}^{-1}$. This gave an average load of $105.05 \mathrm{kWh} \cdot \mathrm{m}^{-2} \mathrm{a}^{-1}$ and a standard deviation of 2.26. This is a significant deviation value when compared with the aspect ratio of $1: 1$ case study above.

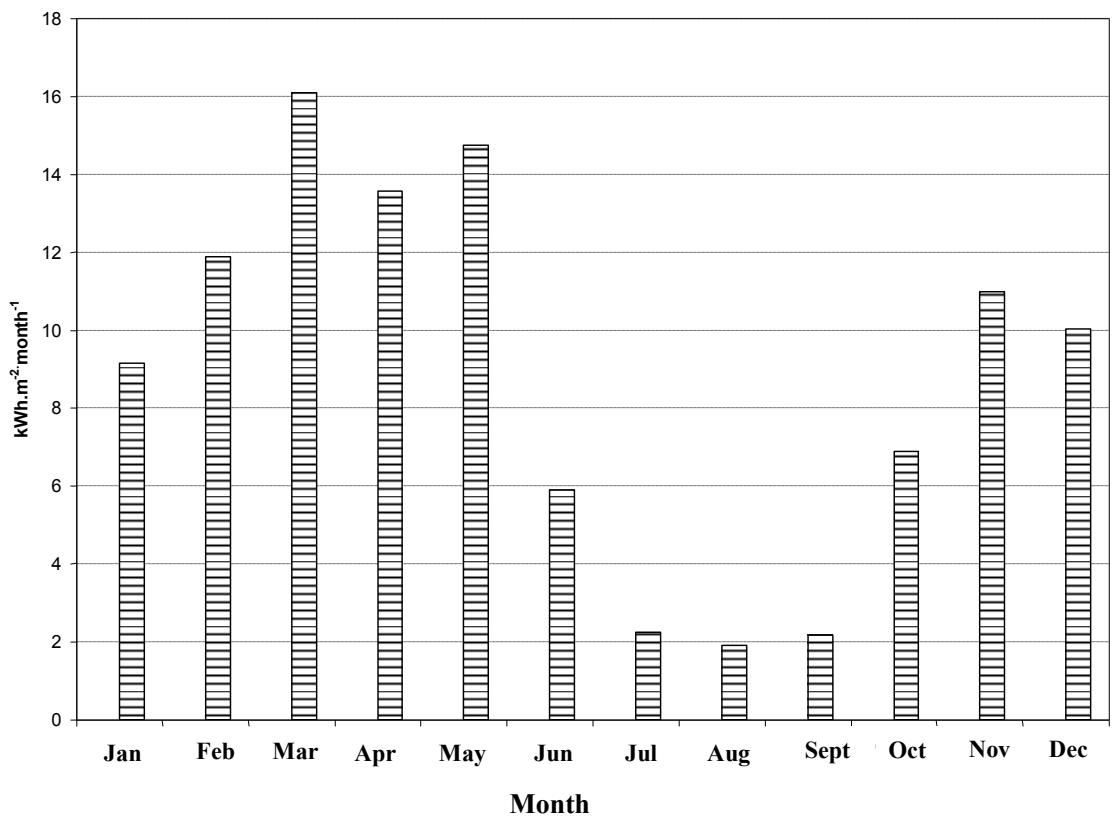

Fig.6: Monthly cooling loads per area at $45^{\circ} / 225^{\circ}$ north orientation (aspect ratio 1:1.5)

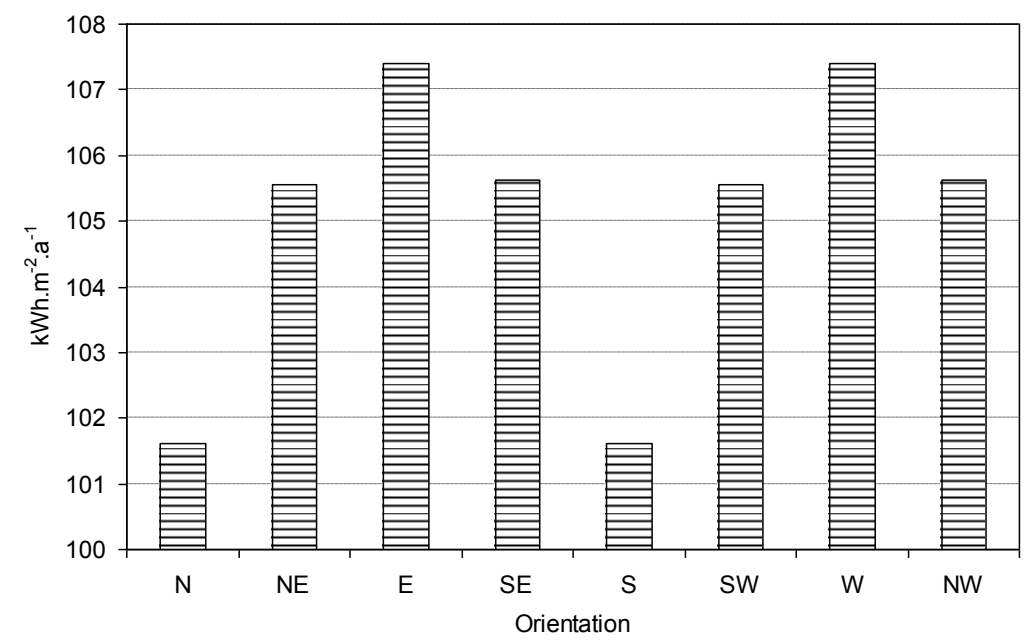

Fig.7: Annual cooling loads per area at different north orientation angles (aspect ratio 1:1.5) 
78 Koranteng and Abaitey

Table 3: Rank of Preferred North Angle Orientation (with 1 being the most and 4 the least preferred orientation) on the Aspect Ratio (1:1.5)

\begin{tabular}{cccc}
\hline Rank & North angles $\left(^{\circ}\right)$ & $\begin{array}{c}\text { Cooling loads } \\
\left(\mathbf{k W h . m}^{-2} \mathbf{a}^{-1}\right)\end{array}$ & $\begin{array}{c}\text { Percentage change relative to } \\
\text { lowest cooling loads (\%) }\end{array}$ \\
\hline 1 & $0 / 180$ & 101.62 & - \\
2 & $45 / 225$ & 105.55 & 3.87 \\
3 & $135 / 315$ & 105.62 & 3.94 \\
4 & $90 / 270$ & 107.41 & 5.70 \\
\hline
\end{tabular}

The preferred order of north angle orientations will be $0 / 180^{\circ}, 45 / 225^{\circ}, 135 / 315^{\circ}$ and lastly $90 / 270^{\circ}$ (Table 3). The percentage increase relative to the $0 / 180^{\circ}$ gives a value of about $4 \%$ for the diagonal angles and $5.7 \%$ when compared to the $90 / 270^{\circ}$ orientations.

Averagely, a percentage change value of 4.5 is to be expected for cooling loads on the different north angle orientations.

The results on the aspect ratio of 1:1.5 show the need to orient elongated buildings to the north and south directions whilst the east and west sides should be avoided as also recommended by, Ferstl (2003).

\section{Aspect Ratio 1:2}

The behaviour of the house form on energy performance, though increasing with the aspect ratios, seems to be similar. At a north angle of $0^{\circ}$ and $180^{\circ}$, the annual cooling load increased to $104.60 \mathrm{kWh} \cdot \mathrm{m}^{-2} \mathrm{a}^{-1}$. This represents an increase of $2.98 \mathrm{kWh} \cdot \mathrm{m}^{-2} \mathrm{a}^{-1}$ as compared to the previous aspect ratio with the same north orientation.

The annual cooling load increased to 110.70 $\mathrm{kWh} \cdot \mathrm{m}^{-2} \mathrm{a}^{-1}$ at a north angle of $45^{\circ} / 225^{\circ}$. This increase was due to solar radiation warming more surface area as compared to the north/ south orientation (Chou 2001).

At $90^{\circ} / 270^{\circ}$ north angles, a further increase of $4 \mathrm{kWh} \cdot \mathrm{m}^{-2} \mathrm{a}^{-1}$ was registered. The annual load on this angle was $114.72 \mathrm{kWh} \cdot \mathrm{m}^{-2} \mathrm{a}^{-1}$ and this shows the eastern and western sun having considerable effects on cooling loads. Comparatively, the difference in increase is twice that at the aspect ratio of 1:1.5 for the same north an- gle orientations even though the area and height have remained constant.

The cooling load decreased from 114.72 $\mathrm{kWh} \cdot \mathrm{m}^{-2} \mathrm{a}^{-1}$ to $110.81 \mathrm{kWh} \cdot \mathrm{m}^{-2} \mathrm{a}^{-1}$ at the north angle of $135^{\circ} / 315^{\circ}$. This gives a difference of $0.11 \mathrm{kWh} \cdot \mathrm{m}^{-2} \mathrm{a}^{-1}$ when compared to the north angle orientation of $45^{\circ} / 225^{\circ}$. This difference is negligible and therefore insignificant. Both diagonal angles could be said to have the same effects on cooling loads.

The summary (Fig.8) shows the maximum cooling loads of $114.72 \mathrm{kWh} \cdot \mathrm{m}^{-2} \mathrm{a}^{-1}$ at east/west orientations and a minimum of $104.60 \mathrm{kWh} . \mathrm{m}^{-}$ ${ }^{2} \mathrm{a}^{-1}$ at north/south orientations. The average cooling load was $110.21 \mathrm{kWh} \cdot \mathrm{m}^{-2} \mathrm{a}^{-1}$ with a standard deviation of 3.87. The standard deviation has increased by 1.50 when compared to that at the aspect ratio of $1: 1.5$.

As the elongated sides increase, so does the cooling load and it is therefore important to be aware of consequences with the use of elongated forms in designs.

Table 4 shows the order of the preferred north angle orientations. The north/south orientations are recommended whilst orientation towards the east/west are to be avoided. This suggests the best orientation for protection from the sun for elongated forms is along the east-west axis. The percentage increase in cooling loads is at a maximum of $10 \%$ at the $90^{\circ} / 270^{\circ}$ north angles. An average of $7.15 \%$ increase in cooling load relative to the preferred north angle orientations of $0^{\circ} / 180^{\circ}$ have been registered.

\section{Aspect Ratio 1:2.5}

The cooling loads increased from 108.80 $\mathrm{kWh} \cdot \mathrm{m}^{-2} \mathrm{a}^{-1}$ at a north angle orientation of 


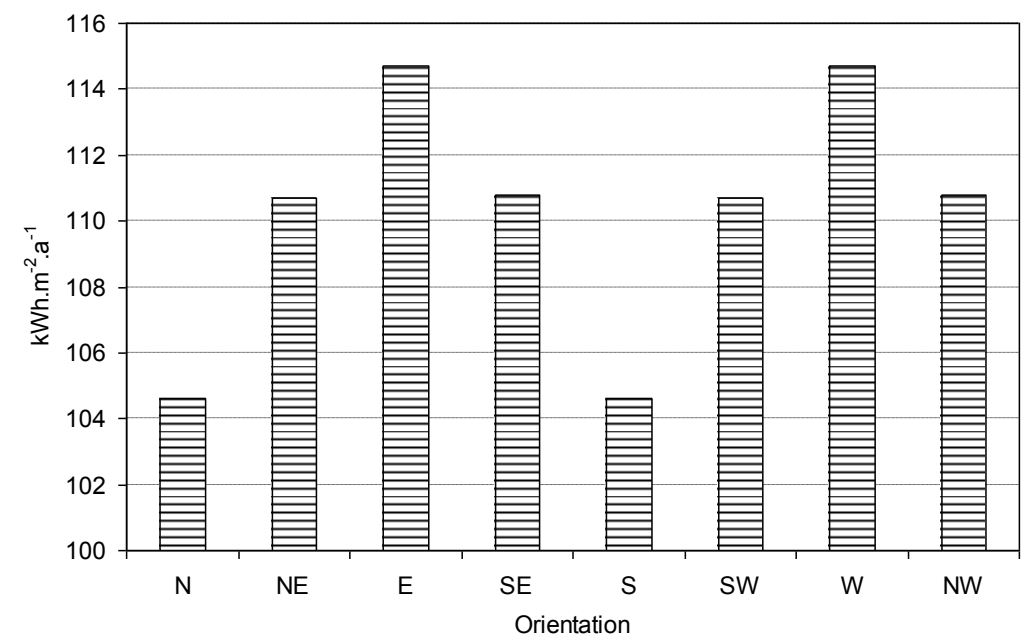

Fig. 8: Annual cooling loads per area at different north orientation angles (aspect ratio 1:2)

$0^{\circ} / 180^{\circ}$ to a maximum of $122.55 \mathrm{kWh} \cdot \mathrm{m}^{-2} \mathrm{a}^{-1}$ at $90^{\circ} / 270^{\circ}$. The diagonal angles recorded 116.74 kWh.m $\mathrm{m}^{-2} \mathrm{a}^{-1}$ at $45^{\circ} / 225^{\circ}$ and $116.89 \mathrm{kWh} \cdot \mathrm{m}^{-2} \mathrm{a}^{-1}$ at $135^{\circ} / 315^{\circ}$. An average load of 116.25 $\mathrm{kWh} \cdot \mathrm{m}^{-2} \mathrm{a}^{-1}$ and a standard deviation of 5.23 showing an increase as compared to that of the previous aspect ratio of 1:2.0.

A north/south orientation can be recommended with this aspect ratio. However, the cooling loads increase by $7.30 \%$ at $45^{\circ} / 225^{\circ}, 7.44 \%$ at the $135^{\circ} / 315^{\circ}$ and $12.64 \%$ at $90^{\circ} / 270^{\circ}$ north angle orientations.

This gives an average value of $9.13 \%$ increase in cooling load relative to the preferred north angle orientation of $0^{\circ} / 180^{\circ}$. In the framework of energy efficient buildings studies, Prajapati (2006) recorded up to $8 \%$ savings in cooling loads when the preferable orientations of northsouth and northeast-southwest were applied.

\section{Aspect Ratio 1:3}

The north angle orientation of $0^{\circ} / 180^{\circ}$ recorded a cooling load of $113.56 \mathrm{kWh} \cdot \mathrm{m}^{-2} \mathrm{a}^{-1}$. At the diagonal angles, values of 123.10 and 123.28 $\mathrm{kWh} . \mathrm{m}^{-2} \mathrm{a}^{-1}$ have been registered for $45^{\circ} / 225^{\circ}$ and $135^{\circ} / 315^{\circ}$ respectively. The maximum load of $130.48 \mathrm{kWh} \cdot \mathrm{m}^{-2} \mathrm{a}^{-1}$ was at the east/west orientations. Averagely, a cooling load of 122.61 $\mathrm{kWh} \cdot \mathrm{m}^{-2} \mathrm{a}^{-1}$ was calculated with this aspect ratio and a standard deviation of 6.43 indicating the difference in loads with alternate orientations.

The percentage change relative to the preferred north angle orientations of $0^{\circ} / 180^{\circ}$ is in the order of $8.40 \%, 8.56 \%$ and $14.90 \%$ for $45^{\circ} / 225^{\circ}, 135^{\circ} / 315^{\circ}$ and $90^{\circ} / 270^{\circ}$ respectively.

Table 4: Rank of Preferred North Angle Orientation (with 1 being the most and 4 the least preferred orientation) on the Aspect Ratio (1:2)

\begin{tabular}{|c|c|c|c|}
\hline Rank & North angles $\left({ }^{\circ}\right)$ & $\begin{array}{c}\text { Cooling loads } \\
\left(\mathrm{kWh} \cdot \mathrm{m}^{-2} \mathrm{a}^{-1}\right)\end{array}$ & $\begin{array}{l}\text { Percentage change relative to } \\
\text { lowest cooling loads }(\%)\end{array}$ \\
\hline 1 & $0 / 180$ & 104.60 & - \\
\hline 2 & $45 / 225$ & 110.70 & 5.83 \\
\hline 3 & $135 / 315$ & 110.81 & 5.94 \\
\hline 4 & $90 / 270$ & 114.72 & 9.67 \\
\hline
\end{tabular}




\section{Koranteng and Abaitey}

With these alternate angles, an average of $10.62 \%$ in cooling loads must be expected with a form aspect ratio of 1:3.

\section{Summary on all Aspect Ratios}

All the rectangular forms showed the least cooling load with an orientation of north/south. The minimum annual cooling load of 101.62 $\mathrm{kWh} \cdot \mathrm{m}^{-2} \mathrm{a}^{-1}$ was recorded with the aspect ratio 1:1.5 for the north/south orientation. This increased with the aspect ratio to $113.56 \mathrm{kWh} . \mathrm{m}$ ${ }^{2} \mathrm{a}^{-1}$ at (aspect ratio 1:3). Averagely, 107.15 $\mathrm{kWh} \cdot \mathrm{m}^{-2} \mathrm{a}^{-1}$ and a standard deviation of 5.19 must be expected with a north/south orientation for the aspect ratios $1: 1.5$ to $1: 3.0$.

With an orientation towards the $45^{\circ} / 225^{\circ}$ or $135^{\circ} / 315^{\circ}$, the minimum annual cooling load recorded was $105.55 \mathrm{kWh} \cdot \mathrm{m}^{-2} \mathrm{a}^{-1}$ and the maximum load $123.28 \mathrm{kWh} \cdot \mathrm{m}^{-2} \mathrm{a}^{-1}$. The average cooling load and standard deviation increased to $114.15 \mathrm{kWh} \cdot \mathrm{m}^{-2} \mathrm{a}^{-1}$ and 7.63 respectively when compared to the north/south orientation.

The maximum cooling loads for all the orientations was at east and west. A minimum of $107.41 \mathrm{kWh} \cdot \mathrm{m}^{-2} \mathrm{a}^{-1}$ and a maximum of 130.48 $\mathrm{kWh} . \mathrm{m}^{-2} \mathrm{a}^{-1}$ have been recorded. This shows an average load of $118.79 \mathrm{kWh} \cdot \mathrm{m}^{-2} \mathrm{a}^{-1}$ with a standard deviation of 9.95 .

It can generally be concluded that for rectangular forms, a north/south orientation must be used whilst an east/west orientation must be avoided. A compromise could be an orientation towards the diagonal angles (Prajapati 2006). However, this must be nearer to the north and south $\left(45^{\circ}\right.$ within southwest/southeast and northwest/northeast) than to the east and west.

Moreover, an aspect ratio of 1:1.5 can be recommended whilst increases of loads up to 7 and $9 \%$ can be expected for the aspect ratios $1: 2$ and 1:2.5 respectively. A compromise of 1:1.75 is ideal, as against the aspect ratio recommendations by, Szokolay (2004) and Watson (1983). This will mean an increase in cooling loads of about $5 \%$ relative to the compact, square shape (aspect ratio 1:1). The advantage in compact building forms is that they gain less heat during the day and loose less heat at night. They also require more artificial lighting, which produces heat that must eventually be cooled (Lechner 2001). The designer should be cautious about spatial disposition and functions for the purposes of thermal comfort. This includes reviewing the building programme and massing (PUDS 2006).

\section{CONCLUSION}

A simulation application was used to study the effects of building form with different aspect ratios and orientation on energy performance. For the purposes of sustainability and energy efficiency, rectangular forms must be oriented towards north/south. While square forms are energy efficient, a detailed look into the function of spaces is recommended.

\section{REFERENCES}

Chou, S. K. (2001). Seminar Proceedings, Energy Efficiency in Building Design: Building Energy Standard, Building and Construction Authority of Singapore, Singapore (18 ${ }^{\text {th }}$ April 2001), paper 2.

EDSL (2008). A-TAS Version 8.5, Environmental Design Solutions Limited, www.edsl.net.

Ferstl, K. J. (2003). Workshop Proceedings, Energy Conserving Concepts in Building Design and Construction, Cooling your Home Naturally, Accra/Ghana $\left(3^{\text {rd }}\right.$ to $7^{\text {th }}$ November 2003), pp 7.

Givoni, B. (1981). Man, Climate and Architecture, Second Edition, Van Nostrand Reinhold Company, New York, pp 213 - 231.

Hawkes, D. (1996). The Environmental Tradition - Studies in the Architecture of Environment, E \& FN SPON, London, pp 36 45.

Koenigsberger, O. H., Ingersoll, T. G., Mayhew, A. and Szokolay S.V. (1974). Manual of Tropical Housing and Building: Part One, Climatic Design, First Edition, Longman Inc., New York, pp 216. 
Lauber, W. (2005). Tropical Architecture, First Edition, Prestel Verlag, Munich, pp 101 105.

Lechner, N. (2001). Heating, Cooling Lighting: Design Methods for Architects, Second Edition, John Wiley \& Sons, Inc., New York, pp 216.

Meteotest (2008). Meteonorm Version 6.0, www.meteotest.ch.

Prajapati, J. (2006). Workshop Proceedings, Design Guidelines for Energy Efficient Buildings, Department of Energy Science and Engineering, Indian Institute of Technology, Bombay, (September 2006), pp 12 $-21$.

Princeton University Design Standards - PUDS. (2006). 3.3 Energy Guidelines, Release 6.0, Page 7, March, www.facilities. princeton.edu/PhysicalPlanning/DesignStandards/,(accessed 2008, January 5).
Salmon, C. (1999). Architectural Design for Tropical Regions, First Edition, John Wiley \& Sons, Inc., New York, pp 124-125.

Szokolay, S. (2004). Introduction to Architectural Science: The Basis of Sustainable Design, First Edition, Architectural Press, Oxford, pp $64-70$.

Watson, D. and Labs, K. (1983). Climatic Design: Energy-Efficient Building Principles and Practices, First Edition, McGraw-Hill Book Company, New York, pp 45, 52, 87 89, 107.

World News Network-WNN (2008). www.article.wn.com/view/2008/01/02/ oil_hits_100_barrel/ (accessed 2008, January 2). 